\title{
Erratum to: Pre-exposure to simultaneous, but not individual, climate-change stressors limits acclimation capacity of Irukandji jellyfish polyps to predicted climate scenarios
}

\author{
Shannon G. Klein ${ }^{1,2}$ (D) Kylie A. Pitt ${ }^{1} \cdot$ Anthony R. Carroll $^{3}$
}

Published online: 7 June 2017

(C) Springer-Verlag GmbH Germany 2017

\section{Erratum to: Coral Reefs}

DOI 10.1007/s00338-017-1590-9

Due to an error in the typesetting process, panels (a) and (b) of Fig. 3 present identical data. Panel (a) of Fig. 3 presents incorrect data but panel (b) presents correct data. To correct this error, we have included a corrected version of Fig. 3.

The online version of the original article can be found under doi:10.1007/s00338-017-1590-9.

Shannon G. Klein

shannon.klein@kaust.edu.sa

1 Australian Rivers Institute - Coasts and Estuaries, Griffith School of Environment, Griffith University, Gold Coast, QLD 4222, Australia

2 King Abdullah University of Science and Technology (KAUST), Red Sea Research Center (RSRC),

Thuwal 23955-6900, Saudi Arabia

3 Environmental Futures Research Institute, Griffith School of Environment, Griffith University, Gold Coast, QLD 4222, Australia 
Fig. 3 Respiration rates of polyps (mean $\pm \mathrm{SE}$ ) preexposed to ambient $\mathrm{pH}$ (a) and reduced $\mathrm{pH}(\mathbf{b})$ conditions recorded at days 1, 4, 14, 24 and

34 of the secondary exposure (days $1-34, n=48$ ). Letters above data points indicate similarities (e.g. $A A$ ) and differences (e.g. $A B$ ) among treatments, as determined by estimated marginal means
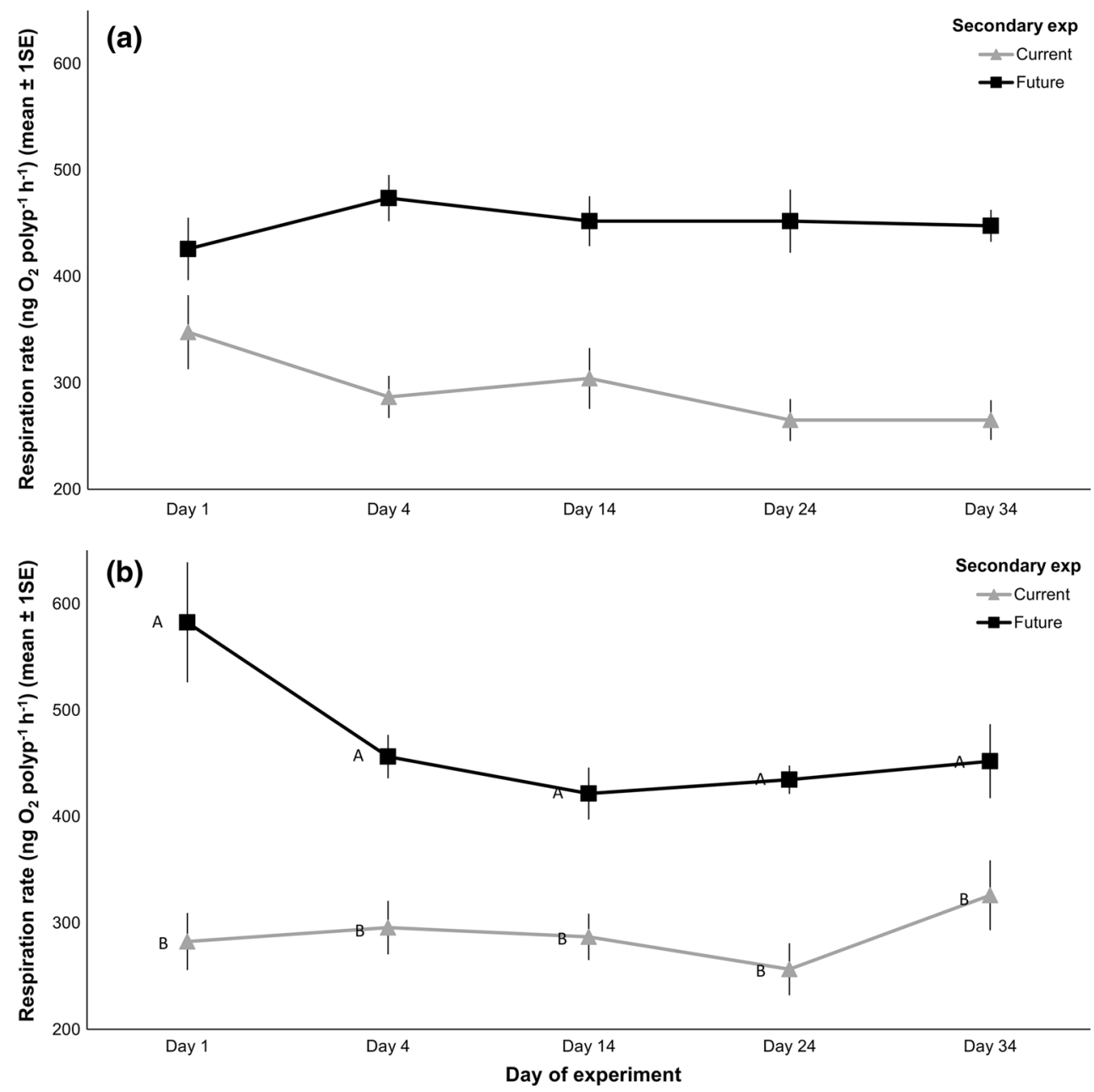